\title{
Arica entre tres fronteras
}

\section{Arica: a City Among Three Borders}

\author{
Haroldo Dilla Alfonso ${ }^{1,2}$
}

\section{Resumen}

Incluida en esa compleja madeja sociohistórica que forman las fronteras chilenas, Arica se distingue por la particular intensidad y diversidad de sus ámbitos y circuitos de relacionamientos transfronterizos. Su realidad como región transfronteriza -moldeada por las acciones desde las comunidades, los mercados y los Estadosconstituye una peculiar imbricación de sus relaciones con sus tres fronteras terrestres -Bolivia, Perú y Tarapacá- y con su puerto que le conecta con el océano Pacífico. Este artículo discute las características de cada una de ellas, la manera como se relacionan para crear un espacio distinguible y los retos que ello implica para el desarrollo futuro de la región.

Palabras claves: regiones transfronterizas, Norte Grande, complejos urbanos transfronterizos, fronteras, Arica.

\begin{abstract}
Arica is part of a dense socio-historical skein that form the Chilean borders, but distinguished by the particular intensity and diversity of its fields and circuits of cross-borders relationships. Its reality as a transborder region - molded by the actions from communities, markets and states - is a peculiar interweaving of its relations with its three land borders: Bolivia, Peru and Tarapacá. And with its port, that connect the region with the Pacific Ocean and the Asian economy. This article discusses the characteristics of each one of them, the way they relate to create a distinguishable territory and the challenges that implies for the future development of the region.
\end{abstract}

Keywords: transborder regions, transborders urban complex, boundaries, Arica.

Recibido: 6 mayo 2016. Aceptado: 20 septiembre 2016

1 Instituto de Estudios Internacionales de la Universidad Arturo Prat, Iquique, CHILE. Email: hdillaalfonso@gmail.com

2 CONICYT Proyecto Fondecyt 1150812, Santiago, CHILE 


\section{Introducción}

La historia del capitalismo -desde los lejanos tiempos en que derrumbaba murallas medievales y se atrincheraba en las ciudades de las costas europeasha sido una secuencia de espasmos de creación destructiva que ha arrasado unidades políticas, etnias e identidades. En consecuencia, ha sido también un continuo proceso de reestructuración territorial al calor -como ha sugerido Tilly (1990) - del contrapunteo incesante entre los ámbitos de la acumulación y los ámbitos de la coerción.

Este artículo intenta dar cuenta de un proceso de rearticulación territorial en la región ${ }^{3}$ administrativa de Arica y Parinacota ${ }^{4}$ en el norte de Chile. Su presupuesto principal es que esta zona se constituye como región transfronteriza (RTF) a partir de la confluencia de cuatro situaciones fronterizas diferentes, y en particular de la que experimenta con la vecina provincia peruana de Tacna. Esta madeja relacional condiciona la vida de Arica, y en particular de su ciudad cabecera, sometiéndola a intensos procesos de intermediación de signos y con resultados

3 El sustantivo región puede tener dos usos en este artículo. Por un lado puede referirse a una unidad administrativa en países que, como Chile, utilizan el término para estos fines. Cuando así sea, lo haré notar. Sin embargo, el uso que predomina en este artículo hace alusión a un proceso de conformación territorial -en los términos que discutiré más adelante- con independencia de sus definiciones políticas o administrativas. Un asunto de pura polisemia que evidentemente necesita ajustes conceptuales que escapan a las posibilidades de este artículo.

4 Arica y Parinacota, con $16.800 \mathrm{~km}^{2}$ y cerca de un cuarto de millón de habitantes, es la región administrativa chilena más joven (creada en 2007), más septentrional, la tercera menos poblada y la cuarta más pequeńa en extensión. Fue también la última anexión territorial chilena (1929) como resultado de la Guerra del Pacífico. Se organiza en dos provincias - Arica y Parinacota- y cuatro municipios. En uno de ellos, correspondiente a la comuna urbana de Arica, vive el $90 \%$ de la población regional. La segunda ciudad en importancia, Putre, es un pequeño poblado altiplánico con unos pocos miles de habitantes y en proceso de despoblamiento. Cuando hablo aquí de Arica me refiero a la región oficialmente denominada Arica y Parinacota. Cuando me refiero al centro urbano, y el contexto lo precisa, hablo de la ciudad de Arica. diferentes. Cada una de estas fronteras hace un uso específico de los espacios y los tiempos, y en cada una de ellas los actores del territorio -pobladores, comunidades, empresarios, políticos, activistas- se ubican en relación con las ganancias diferenciales que toda situación fronteriza genera.

Las ideas que aquí expongo tienen, como el lector advertirá, un tono polémico $y$, de hecho, son presentadas de una manera ensayística. Ello persigue un objetivo vital para el trabajo académico: incentivar el debate como herramienta epistemológica, calistenia inseparable de aquello que Morin (2000, p. 59) llamaba "el derecho a la reflexión [en contraposición a] la confrontación ciega de los hechos o la verificación testaruda de hipótesis fútiles". Pero, obviamente, no implica que se trate de reflexiones simplemente especulativas. Las ideas que aquí presento son parte de los resultados de una investigación con base empírica, en el marco del proyecto FONDECYT 1150812 antes mencionado, que se desarrolla sobre el eje espacial Arica/Tacna a partir de la identificación y estudio de una serie de ámbitos y circuitos (transaccionales, públicos, migratorios, íntimos, perceptivos) que construyen la RTF.

Con vista a avanzar hacia una discusión más sustancial, es imprescindible acercarnos a una definición funcional de dos conceptos centrales que emplearemos: región y transfrontericidad.

Para entender el primero (como antes decía, más allá de la simple formulación administrativa) es útil remitirlo a la noción de sistema, lo que nos obliga a dos precisiones. Per se, la región resulta, ante todo, un sistema espacio/temporal que gravita en torno a una economía política, al decir de Harvey (2003, p. 88) de "coherencia estructural en la producción, distribución, intercambio y consumo", y a un entramado de prácticas sociales, políticas públicas y de cotidianeidades. Pero al mismo tiempo, la región es un concepto relacional que se define desde sus intercambios con un entorno, del que se distingue (de ahí su carácter autorreferente) pero al mismo tiempo se vincula de manera contradictoria, haciendo del conflicto la razón de su dinámica. Todo sistema -también las regiones- posee una cierta cualidad autopoiética, que nos permite referirnos a él como 
unidad actuante para determinados niveles de nuestro análisis. ${ }^{5}$

Una de las modalidades de regionalización más complejas tiene lugar cuando contienen sistemas territoriales transfronterizos. Un fenómeno cada vez más usual en la misma medida que el capital -con su irrefrenable vocación para desvanecer todo lo sólido en el aire- da cuenta en sus calistenias territoriales de aquellos lugares de la geopolítica westfaliana que constituyeron el test case de la obra política más sagrada de la modernidad: los límites estatales nacionales. Se trata de la subversión crematística de las fronteras internacionales, sus relativizaciones, abriendo compuertas en unos casos, cerrándolas en otros. Y siempre conviviendo con huecos que, al decir de Leimgruber (2005), han terminado siendo tan notorios como los muros que los contienen.

En este punto conviene detenernos brevemente en la conceptualización de "lo transfronterizo" y de las regiones que se inscriben en esta modalidad. El término hace alusión a una situación específica de relación internacional que concierne a franjas fronterizas en contacto. Ciertamente se trata de una relación internacional, pero refractada por un prisma local en que confluyen la dinámica específica de los capitales en estos lugares, las configuraciones de las sociedades particulares y las concertaciones políticas. Existe una notable bibliografía que ha dado cuenta de este tipo de relación y de articulación territorial regularmente compuesta por estudios enfocados a los procesos ocurridos en la frontera entre México y Estados Unidos, y en Europa. Y entre ellos se destacó un artículo seminal de Bob Jessop (2001), inicialmente publicado bajo un sugerente título: $\mathrm{La}$ economía política de la escala.

El artículo de Jessop - un economista fructíferamente anclado en la tradición neomarxista del regulacionismo- realizó listados exhaustivos de formas de "relativización de las escalas" y de los itinerarios que éstas siguieron para conformar las RTF. No hay espacio aquí para recrear esta enumeración que, de cualquier manera, pudiera mostrar más de una fisu-

5 Aun guardando distancia de sus postulados más funcionalistas, sugiero a Luhmann (1997) para una definición de los atributos sistémicos antes mencionados. ra tras tres lustros de exposición a la crítica de sus sucesores. Pero es indudable que puso sobre el tapete dos asuntos que resultan claves para nuestra discusión. El primero, el carácter multicontextual en que tienen lugar estas configuraciones territoriales, de manera que la relativización escalar ocurre en situaciones diferentes que inducen resultados igualmente variados. El segundo, ligado a lo anterior, la diversidad de los itinerarios.

En consecuencia, cuando aquí hablo de región transfronteriza (RTF) me estoy refiriendo a, 1) una situación multidimensional, multiescalar y jerárquica que implica, 2) la generación de un sistema espaciotemporal que abarca territorios contiguos bajo jurisdicciones nacionales diferentes, y 3 ) regularmente organizado en torno a ejes urbanos que se constituyen en complejos urbanos transfronterizos (Dilla, 2015). ${ }^{6}$ Como toda región, las RTF se forman desde las estrategias de acumulación, desde las prácticas sociales (contestatarias, adaptativas, complementarias) y desde políticas públicas. Lo que las distingue es la agregación de un nuevo eje de conflicto -precisamente la condición transfronteriza- y la manera como este eje -y los actores que en él se muevenacentúan la difuminación de las propias escalas. Este último rasgo -las escalas difuminadas- es sin lugar a dudas un rasgo notorio de las RTF.

\section{Chile y sus fronteras multicontextuales}

Basta observar las hileras interminables de camiones bolivianos entrando al puerto de Arica, los agolpamientos de todo tipo en el paso Los Libertadores, la displicencia de los bordes australes, para entender que las fronteras chilenas son espacios complejos.

Las ciencias sociales han tomado nota de ellas. Sin embargo, a pesar de los alcances conseguidos en el último lustro, los estudios fronterizos en Chile son

6 Defino el complejo urbano transfronterizo como un istema urbano que articula una región transfronteriza, y en el que al menos dos ciudades comparten un entorno ambiental, son económicamente interdependientes, poseen fuertes vínculos sociales primarios, así como concertaciones dadas en el terreno público, y sus habitantes reconocen una mutua imprescindibilidad. 
aún incipientes. Y salvo las excepciones de rigor, tienen dos características limitantes. La primera -derivada del anclaje del nacionalismo metodológico y del acicate de las coyunturas políticas- es la persistencia en ellos de las facturas geopolíticas, de manera que el tema de las fronteras sigue siendo en la academia chilena, en buena medida, el tema de los límites. En segundo lugar, los estudios que han rebasado esta camisa de fuerza $-y$ piensan las fronteras como espacios sociales distintivos- son celosamente disciplinarios - probablemente con la honrosa excepción de los estudios de historia social-, reproduciendo a escala nacional un déficit señalado por Brettel y Hollifield (2015) para el tema de las migraciones: la carencia de paradigmas compartidos y la existencia de una situación de fragmentación que dificulta una acumulación de conocimientos en beneficio de la teorización (Dilla, 2016).

De cualquier manera, habría que reconocer que el tema de las fronteras chilenas es de una complejidad mayor, lo cual puede ser un estímulo para el ejercicio intelectual, pero en ocasiones -cuando se trata de esfuerzos intelectuales emergentes- puede resultar un obstáculo epistemológico considerable. Chile es uno de los países de dimensiones regulares con mayor longitud de fronteras en relación con su área, de manera que contra sus casi 8 mil km lineales de

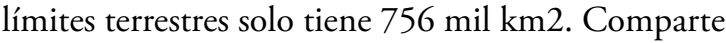
estas fronteras con tres países, con los cuales mantiene conflictos posicionales, vivos o adormecidos. Y por ello, y por razones de la historia, contiene una diversidad impresionante de situaciones fronterizas, un entramado particularmente enredado que dificulta cualquier esfuerzo de generalización, sea desde la teoría o desde la gestión pública.

La mayor parte de la línea fronteriza terrestre chilena -el $85 \%$ de ella- es compartida con Argentina, marcada generalmente por los puntos más altos de los picos andinos, y donde se ubican 27 de los 33 puestos fronterizos existentes. Es una línea histórica y socialmente discontinua que Benedetti y Laguado (2013, p. 453) calificaron como “...una entidad en permanente tensión con una multiplicidad de espacialidades que se despliegan en forma multiescalar". En otras palabras, una caja de pandora de situaciones fronterizas distintas que solo recientemente comienzan a ser expuestas en algunos meritorios proyectos académicos que han englobado a investigadores de ambas partes y que han pensado a los Andes como una cordillera para cruzar (Núñez et al., 2013).

$\mathrm{Al}$ norte, este segmento de frontera combina páramos desolados con puntos de tráficos comerciales y humanos relativamente intensos, como ocurre en el paso de Jama que contacta Antofagasta con la provincia argentina de Jujuy. En el centro, la zona cuyana, la frontera se reanima, lo que posibilita, según Claudio Maiz (2007, p. 115), "plantear la hipótesis de concebir dicho conjunto como partes de un mismo territorio", como portales en lugar de muros. Es justamente aquí, donde la frontera cobra su sentido de frontera internacional, con el Paso Los Libertadores y sus muchos millones de toneladas métricas de cargas y de personas. Al sur, donde los Andes comienzan a disolverse en las planicies de la Patagonia, la frontera chileno-argentina alcanza su mayor dimensión humana, en una miríada de contactos aprehensibles desde la intimidad de la etnografía.

Cuando la frontera linda con Bolivia, cobra otro sentido. Sus casi $900 \mathrm{~km}$ de largo, custodiados por cinco puestos fronterizos, son un reto a la geografía y a la geopolítica. A pesar de la altura de los Andes en este punto y de las pésimas relaciones interestatales entre Chile y Bolivia, esta frontera es particularmente activa a partir de tres dimensiones. La primera, es el uso por parte de Bolivia de las instalaciones comerciales chilenas, particularmente de la Zona Franca de Iquique y del puerto de Arica. La segunda, un intenso cruce de personas atraídas por las ofertas laborales chilenas, sea en las zonas mineras o en los cordones agrícolas de Lluta y Azapa en torno a Arica o en cruce hacia regiones más distantes, argentinas o chilenas. $Y$ finalmente, una relación ancestral compartida -ese mundo aymara, al decir de Albó (2000), resistente a las fronteras cambiantes- y que dio lugar a una de las experiencias políticas transfronterizas más interesantes en el continente: Aymarás sin Fronteras (Aranda, Ovando y Corder, 2010).

La frontera con Bolivia puede ser dividida en dos partes. La primera tiene su hito distintivo en el cerro de Zapaleri, vórtice del trifinio que pone en contacto a las regiones del Potosí boliviano con Antofagasta y Tarapacá -dos adquisiciones chilenas de la 
Guerra del Pacífico- y las provincias argentinas de Jujuy y Salta, ambas alimentadas con otros despojos territoriales de Bolivia. Desde esta interacción territorial se ha generado una intensa región transfronteriza que permitió la proeza humana de revalidar el desierto como espacio y tiempo, "un fenómeno social, escribió González, concreto, complejo, contradictorio y culturalmente denso" (2013, p. 217). $\mathrm{Y}$ en la actualidad es el paso predilecto de millones de dólares de mercancías que van y vienen hacia las instalaciones portuarias y comerciales chilenas desde y hacia las economías interiores. Por ello, no es casual que sea donde se han originado los estudios chilenos que han reclamado con más vigor una conceptualización de las regiones transfronterizas como fenómenos sociales relevantes (Dilla, 2016).

Cuando el límite boliviano-chileno sigue corriendo al norte y entra en relación con la provincia de Arica -otro trofeo chileno de la Guerra del Pacífico (1879-1883) - desemboca en un segundo trifinio, en este caso compartido con Perú. Y desde él, comienza el tercer segmento de la frontera: un borde de unos $170 \mathrm{~km}$ que pone en contacto la región administrativa chilena de Arica y Parinacota con la provincia peruana de Tacna, para dar lugar al segmento de frontera más denso y complejo de toda la geografía chilena.

En los bordes externos ariqueños funcionan tres puestos fronterizos, dos compartidos con Bolivia, Chungará-Tambo Quemado y el diminuto Visviri, y el tercero, él único que existe en la frontera con Perú, Chacalluta-Santa Rosa. En total, según los informes de aduanas para 2014, circularon por ellos 3,4 millones de toneladas de mercancías y algo más de 6 millones de personas. En Arica se encuentra el puerto que Bolivia usa preferentemente para sus exportaciones, y así ha sido históricamente. Y finalmente, es el único lugar de toda la frontera en que dos ciudades de tamaño regular-Tacna y Arica- se encuentran íntimamente conectadas.

En resumen, estamos en presencia de una diversidad de situaciones que abren espacio a diferentes modalidades de formación y funcionamiento de regiones transfronterizas (RTF). Y, lo que pudiera resultar más interesante, de un fenómeno espacio-temporal que se incrementará y devendrá más complejo en el futuro, en la medida en que más actores locales suramericanos se interesen por utilizar el extenso portal marino chileno para asomarse al océano Pacífico, el mar por excelencia del capitalismo líquido del siglo XXI.

\section{Arica en sus fronteras}

La ciudad de Arica resulta - para el visitante medianamente informado- un lugar que fascina y desconcierta. La vista de la ciudad está dominada por un hito natural, el Morro, cuya meseta superior alberga un museo destinado a conmemorar una batalla decisiva -y particularmente sangrienta- de la Guerra del Pacífico, que ocurrió en ese lugar en 1880. Es, probablemente, el museo más sombrío de toda la geografía chilena -donde la muerte es recordada briosamente- $y$ donde aún se alude a la buena mano del dictador Augusto Pinochet.

A los pies del Morro yace lo que se denomina el Arica Peruano, es decir el fragmento más antiguo de la ciudad, donde junto a piezas arquitectónicas de varios tipos y estilos, se alza una oficina consular peruana coronada por lo que pudiera ser una de las banderas más grandes que adornan la ciudad: una tela rojiblanca que es imposible no ver desde cualquier ángulo del centro.

La casa se denomina de Bolognesi, pues fue allí donde un general peruano, Francisco de Bolognesi, comunicó a los mandos chilenos su decisión de resistir hasta la muerte, aun sabiendo que la resistencia tenía inevitablemente ese costo. Otros lugares llevan el nombre del aguerrido oficial. Uno es un paseo comercial de Arica, donde curiosamente se levanta un monumento al roto chileno, arquetipo del nacionalismo que Bolognesi retó en el morro. Y allende la frontera, en Tacna, una importante arteria lleva el mismo nombre. Es la avenida que alberga los principales centros comerciales que los ariqueños - millones de visitantes cada año- usan para diversos fines, incluyendo la celebración lúdica de sus fechas patrias durante los días de asueto. Ocasión en que los comerciantes tacneńos engalanan sus locales con banderas y otras alegorías chilenas. 
Toda frontera habitada contiene un toque de hibridación cultural y solapamiento de las escalas (internacional, nacional, local) que viabiliza la vida de sus habitantes - muchos de los cuales son habituales cruzadores de fronteras-, pero que es percibida desde los centros como anomias crónicas. Las fronteras chilenas no son excepción. Pero también habría que reconocer que en el caso específico de Arica, tratamos con una situación particularmente compleja, incluso en relación con su medio sociohistórico distintivo: el Norte Grande. ${ }^{7}$ De manera que, la conversión de la región en zona fronteriza y de la ciudad en geosímbolo (González, 2010) ha transcurrido en medio de una serie de vicisitudes históricas que han colocado a su sociedad en una situación de disonancia identitaria. Como todo espacio de frontera, el signo distintivo de Arica es la heterotopía cotidiana, tal y como lo definía Foucault (2008), la yuxtaposición en un lugar real de varios espacios que normalmente serían, o deberían ser, incompatibles.

Nada de esto es ajeno a un hecho histórico: su muy tardía incorporación de jure a la nación. Aunque la ciudad estuvo en manos de Chile desde la Guerra del Pacífico (1879-1883), no fue sino hasta 1929 que su incorporación legal fue realizada mediante un acuerdo binacional que anexó Arica y restituyó Tacna a Perú. Obviamente, la presencia del Estado chileno fue un hecho en el casi medio siglo de ocupación interina (1883-1929), en ocasiones al costo de fuertes sufrimientos humanos derivados de las políticas de chilenización forzada y de limpieza étnica. Pero durante mucho tiempo -y aquí vuelvo nuevamente a González (2009)- el Estado chileno valoró Arica como una posible solución a la salida boliviana al mar. Lo cual no solo encajaba con las aspiraciones de este último país, ${ }^{8}$ sino que

7 El término Norte Grande hace referencia fundamentalmente a los territorios del norte de Chile que fueron anexados manu militari como consecuencia de la Guerra del Pacífico. Incluye, además de la región administrativa de Arica y Parinacota, las de Tarapacá y Antofagasta, con las ciudades de Iquique y Antofagasta como cabeceras. Las dos primeras fueron expropiadas a Perú, y la última a Bolivia.

8 Un documento oficial boliviano de los ańos veinte del siglo pasado era tan directo como conmovedor: "Arica, respecto de Bolivia, llena la función de un órgano vital. Respecto del Perú y de Chile, con cuya vida no tiene conexión alguna, sólo es un medio de intervención one- no debió resultar extraño a una población local que históricamente había mostrado ciertos afectos básicos y un reconocimiento de necesidad respecto al vecino oriental.

Para los ariqueños que vivieron las medianías del siglo XX, la relación con los dos perdedores de la guerra era imprescindible para la sobrevivencia. Y, en consecuencia, siempre sostuvieron vínculos diversos que incluyeron un intenso movimiento de personas, lo que en el caso de Perú se materializó a través de un acuerdo de paso libre por períodos limitados de tiempo, y respecto a Bolivia, como siempre había sido, mediante el uso del puerto.

La intermediación transfronteriza de la ciudad y la región, en consecuencia, se realizó respecto a dos fronteras internacionales terrestres. Pero no fueron las únicas fronteras. Cuando la zona fue incorporada legalmente a Chile, y en particular a lo que hoy constituye la región de Tarapacá encabezada por la ciudad de Iquique, entró en un contrapunto antitético respecto a su centro político-administrativo local. Los ariqueños tuvieron que convivir con una condición fronteriza múltiple, lo que determinó incidencias y reacciones diferentes desde la sociedad local, así como retos muy particulares para la planificación de su desarrollo.

Y, finalmente, el puerto, es decir, la frontera marítima de Arica. Carole Hein (2011) en un sugerente libro ha resaltado el rol histórico de los puertos en la creación de ciudades. Desde ellos, éstas experimentan formas específicas de interacción de lo global y lo local, que modelan sus espacios y sus tiempos. La ciudad de Arica no ha sido diferente.

De hecho, la ciudad nace como un puerto. Y cuando en la segunda mitad del siglo XVI le fue concedido un escudo de armas, su campo fue ocupado de manera apabullante por el dibujo de una elevación que algunos ariqueños han querido identificar con el icónico Morro, pero que en realidad alude al cerro Rico de Potosí, en lo que hoy es Bolivia: una monta-

rosa sobre la vida económica boliviana. Para el Perú y para Chile es un sitio, un lugar de administración, un vecindario. Para Bolivia es un puerto. Por Arica no se va al Perú ni se sale de Chile. Arica es la puerta exclusiva de Bolivia” (citado por Brockman, 2014, p. 83). 
ña de plata que alimentó al capitalismo europeo por un siglo y medio, y cuyos cargamentos eran embarcados en el puerto de Arica. Arica es, en el escudo, una simple alegoría al mar. La ciudad quedó configurada como un espacio intermediario entre procesos económicos que no controlaba. De manera que la región ha estado históricamente llamada a intermediar y metabolizar flujos económicos de magnitudes mayores, con oportunidades y externalidades negativas incluidas. Pero que, por la naturaleza de la intermediación en calidad de un pontón bisagra, en ningún caso produjo despegues desarrollistas endógenos: no hubo -como en otros puertos continentales- acumulación sostenida ni una especialización suficiente en beneficio del capital humano local.

El puerto sigue siendo vital para Arica. De hecho, es uno de los más importantes y modernos de Chile. Pero, al igual que en el siglo XVI, el puerto sigue siendo un enclave, pues el $80 \%$ de sus cargas corresponde a mercancías bolivianas tramitadas al calor del acuerdo de 1904. Por consiguiente, la ciudad se beneficia de algunos empleos, directos e indirectos, pero, a cambio, es acosada por el uso de sus calles y espacios, el secuestro de su frontis marino - un recurso paisajístico de primer orden- y la contaminación atmosférica y acústica.

A los fines de este trabajo, no es difícil percibir el puerto como otra frontera, en este caso con la economía/mundo, tal y como la definió Wallerstein (1999). Ciertamente, una frontera secuestrada por los imperativos de la geopolítica. Pero que tiene dos implicaciones para el tema que trato. Primero, resulta un ordenador de los ámbitos y circuitos transfronterizos en relación con los límites terrestres, básicamente con Bolivia. Y en segundo lugar, porque, como discutiré en las conclusiones, el puerto contiene un potencial transformativo mayor si los proyectos de regionalización bioceánicos consiguieran materializarse.

\section{La frontera descolgada}

Arica tiene al este su frontera histórica: Bolivia. Como antes anotaba, durante la época colonial, el puerto de Arica -en torno al cual fue organizándose la ciudad- fue la vía de salida de los metales precio- sos del Potosí. Este sigue siendo el signo del contacto con Bolivia. Ahora a la sombra de un tratado chileno-boliviano que en 1904 trató de remediar las secuelas de la Guerra del Pacífico estableciendo el uso libre de los puertos chilenos por parte de una Bolivia, que había quedado sin mar tras la pérdida de Antofagasta.

De esta manera, Arica funciona a los fines bolivianos, como un corredor para el tránsito de las mercaderías desde y hacia el eje La Paz-Oruro; y su ciudad cabecera como un muelle para salir al Pacífico. En un primer momento, la conexión se hizo a través de un ferrocarril y actualmente por carreteras que atraviesan la geografía ariqueña para internarse en territorio boliviano, principalmente por el Paso Chungará-Tambo Quemado. Según las estadísticas aduaneras chilenas (Aduanas, 2017), por Chungará ingresaron 1,1 millones de toneladas de mercancías y salieron 1,9 millones, un volumen de carga total cercana a los 3 millones. Según los conteos de aduana, esto puede reportar más de 500 vehículos de carga diarios.

Por su parte, según la memoria técnica de ese mismo año, el puerto de Arica (TPA, 2017) había procesado un total de 2,5millones de toneladas métricas de mercancías bolivianas, el $79 \%$ de sus operaciones. Esta participación ha ido creciendo, a espaldas de las querellas diplomáticas entre ambos Estados, y hoy engloba cerca de 7 mil empresas bolivianas de todas las dimensiones. Finalmente, Bolivia posee un oleoducto -Sica Sica- que recorre $150 \mathrm{~km}$ desde el puerto hasta el litoral y que hace parte de su trayecto por una de las avenidas más populosas de la ciudad. Esta instalación se complementa con una terminal petrolera y con un área de 17 ha en función del almacenamiento de combustibles, todo a cargo de Yacimientos Petrolíferos Bolivianos.

Obviamente, la relación transfronteriza con Bolivia no puede ser reducida a este típico tráfico internacional de mercancías marcado por las secuelas de una guerra decimonónica. A lo largo del límite común, se producen numerosos intercambios transfronterizos con impactos locales, lubricados por la compartición de una identidad ancestral aymara que ha dejado su impronta en la cultura regional. Es aquí, y en este 
mismo contexto, donde la experiencia de concertación intermunicipal Aymará sin fronteras gozó de mayor dinamismo. Y desde aquí, miles de campesinos bolivianos "descolgados" cruzan un borde inamistoso, sea para continuar camino hacia otras zonas, sea para trabajar en los predios agrícolas de Lluta y Azapa. En la propia ciudad los bolivianos son parte inseparable del paisaje, y varios concurridos lugares urbanos pueden ser considerados como espacialidades propias. Según las estadísticas oficiales, el $42 \%$ de los inmigrantes en Arica son bolivianos. Solo en 2014 ello significó el ingreso de algo menos de 300 mil personas, el 70\% hombres, y el $88 \%$ por el puesto de Chungará-Tambo Quemado, una parte signficativa de los cuales eran choferes de camiones de carga. ${ }^{9}$ Un total de 1206 nińos y adolescentes bolivianos ocupaban plazas en el sistema de enseñanza básica y media de la región, el $2 \%$ de todos los estudiantes y el $52 \%$ de los extranjeros (Seremi, 2015)..$^{10}$

Pero aun asumiendo estos datos, la relación transfronteriza con Bolivia afronta limitaciones considerables. La geografía de la frontera es agreste, muy poco poblada y abrumadoramente rural. La configuración cultural de la región es aymara a ambos lados del borde, lo que inevitablemente disuelve diferencias que siempre se hacen notar en una frontera. Los bolivianos no tienen a Chile como un destino migratorio preferido, sino Argentina, por lo que, para muchos, Chile es un "no lugar" que conviene dejar atrás y ellos mismos no son otra cosa que transeúntes. Y finalmente, debido al sempiterno conflicto fronterizo, no existen espacios interestatales de coordinación, que en otros casos han servido de cajas de resonancia de contactos diversos al nivel de los funcionarios locales y de la sociedad civil.

9 La información estadística migratoria citada más adelante, salvo otra indicación específica, proviene del $\mathrm{Mi}$ nisterio del Interior y Seguridad Pública, solicitada en el marco de la Ley de Transparencia 20.285.

10 En virtud de los acuerdos migratorios del Mercosur, los ciudadanos bolivianos tienen la opción de entrar a territorio chileno portando solo el documento de identificación de su país cuando se trata de visitas de turismo, o solicitar residencia para todos los fines mediante pasaportes actualizados. No obstante, debido a las dificultades para obtener la documentación -en Bolivia y en Chile- muchos de estos inmigrantes son indocumentados y prefieren transcurrir ocultos en la identidad ancestral compartida.
En términos socioeconómicos es, sin lugar a dudas, un corredor internacional (Félix et al., 1997), es decir, un eje adaptado a las infraestructuras viales por el que circulan mercancías, personas, información, pero sin llegar a generar aglomeraciones productivas y de servicios. En consecuencia, solo es posible colegir desde estas relaciones una región transfronteriza incipiente y fragmentada. Digamos que latente. Sobre todo cuando la contrastamos con otra relación transfronteriza: la que Arica sostiene con la provincia de Tacna, ubicada en Perú, y que transita por un solo puesto fronterizo, Santa Rosa-Chacalluta.

\section{La frontera para cruzar}

Si el dato empírico de la frontera boliviana es el paso incesante de inmensos camiones de carga, el de la frontera con Perú es el tránsito de personas en ambas direcciones, de todas las maneras y con todos los fines posibles. Es, en este sentido, una completa alegoría a la noción de la frontera viva.

El puesto de Chacalluta-Santa Rosa -que regula el tránsito entre Arica y Tacna- no tiene la relevancia comercial formal de Chungará-Tambo Quemado. Según los datos de Aduana (2017) por este puesto transitaron algo más de medio millón de toneladas métricas de mercancías, de las cuales solo cantidades menores correspondían propiamente a un comercio entre Chile y Perú. La mayor parte de este monto era carga en tránsito, moviéndose hacia y desde Bolivia por territorio peruano, o mercancías peruanas provenientes de puertos ubicados al norte, o desembarcadas en el propio puerto de Arica. ${ }^{11}$

Este trasiego tiene cierta importancia para la vida de Tacna -por ejemplo, para el suministro de mercancías asiáticas a la zona franca comercial (ZofraTacna) - e impacta positivamente en la ciudad de Arica debido a que buena parte del transporte es realizado por empresas chilenas, a diferencia del tráfico boliviano que solo involucra a transportistas de ese

11 El gobierno peruano retiene el control administrativo de un muelle en el puerto para usos comerciales propios (otra secuela de los arreglos postbellum), pero en condiciones técnicas tan precarias que solo puede usarse de dos maneras: físicamente como almacén y simbólicamente como artificio legal que ha permitido la entrada de mercancías por otros espigones del puerto. 
país. Pero se trata de una actividad menor comparada -como ha quedado dicho-, con la movilidad de personas.

El puesto fronterizo de Chacalluta puede considerarse como uno de los más transitados por personas en el continente. En 2017 (según las estadística de Aduana, 2017), se produjeron 3297847 ingresos de personas a territorio chileno por este punto, y salieron por él 3229 959, es decir, más de seis millones y medio de cruces anuales. Más del 95\% de estas personas eran chilenas o peruanas, casi a partes iguales.

Este simple dato coloca el asunto en una dimensión diferente a lo que sucede con el borde boliviano. En realidad, se trata de un tipo de vinculación que no puede ser reducida a una clásica relación internacional. Obviamente, hay dos jurisdicciones nacionales que entran en contacto, y funcionarios encargados de recordarlo. Persiguen con energía variable tanto el contrabando como el narcotráfico y el tráfico de personas, y recientemente el Estado chileno ha puesto en funcionamiento un plan especial denominado Plan Frontera Norte dirigido a contener "nuevas amenazas" relacionadas con el tráfico de cocaína desde Perú y Bolivia; y marihuana desde Paraguay (García, 2015). ${ }^{12} \mathrm{Y}$ en ocasiones resurgen las viejas disputas territoriales sin más valor que el simbolismo político, como es el caso del diferendo chileno-peruano por un triángulo rocoso costero de 3 ha de superficie.

Pero los ámbitos y circuitos de relacionamientos funcionan aquí con una fuerte lógica transfronteri$\mathrm{za}$, es decir, de vinculaciones de las sociedades y las economías locales, y así son percibidas por ariqueńos y tacneńos. Obviamente lo hacen al calor de la relación binacional -de la que son parte específica-, pero también a pesar de ella, en particular cuando Santiago y Lima se enredan en conflictos que a nadie conviene en estos mundos de fronteras. Aun cuando sean relaciones que en más de un sentido se conectan con la economía global, siempre cargan consigo una cuota significativa de relaciones personales primarias y cotidianas que las viabilizan y le otorgan un sello socioantropológico particular.

12 Una interesante aproximación desde el periodismo de investigación a estas zonas negras y grises de la frontera puede hallarse en Peña (2009).
La circulación de personas es la manifestación visible de un entramado muy complejo de relaciones que tiene lugar en diferentes ámbitos y mediante una infinidad de circuitos, incidentes tanto en las economías familiares como en la formación de bolsones "grises" de acumulación. Y aunque en ocasiones pueden resultar negocios medianos y grandes, dan siempre la impresión de acomodos moleculares en los intersticios de la formalidad.

Es así como una parte significativa del millón y medio de cruces de peruanos hacia Chile son migrantes. Una porción de ellos sigue viaje al sur, aprovechando las ventajas migratorias de la Alianza del Pacífico y cuidándose de las miradas de los oficiales chilenos, cuyos poderes discrecionales rebasan lo que un buen orden migratorio aconsejaría. Pero otra parte se queda en Arica, suplantando a los ariqueños que salen a trabajar a regiones minero-exportadoras con mayores oportunidades salariales.

Ellos constituyen el soporte principal de la economía agrícola ariqueña que tiene lugar en Lluta y Azapa (Vicuña y Rojas, 2015), ${ }^{13}$ y en no menor medida de una gama de actividades comerciales. Son los usuarios regulares de un mercado laboral precario que Tapia (2015) ha analizado como una movilidad circular (Tarrius, 2000), con sus múltiples implicaciones estructurales y existenciales. Y desde ellos se despliega una infinidad de prácticas sociales y tácticas de sobrevivencia cotidianas que constituyen el meollo del ámbito económico compartido entre ambas ciudades. Son, huelga anotarlo, una pieza clave de la reproducción capitalista en la región, haciendo realidad ese sueńo de la acumulación que Kearney (2003, p. 49) describía como "la separación espacial de los sitios de compra y consumo de la

13 Desde el mismo momento de la separación, quedó establecido un acuerdo de libre tránsito de peruanos y chilenos en ambas direcciones, mediante el denominado Acuerdo Tacna-Arica. Ello permitía pasar al otro lado y permanecer por una semana sin realizar labores pagadas, y sin derecho a seguir camino por los respectivos territorios nacionales. De ahí la existencia de un puesto fronterizo en la frontera de Tacna con Tarapacá. Desde 2013 los peruanos pueden entrar libremente al territorio chileno como turistas portando solo la cédula de identidad, en virtud de la llamada Alianza del Pacífico. No obstante, no están autorizados a realizar actividades lucrativas. 
mano de obra desde los sitios de su reproducción". No es casual que, a pesar del altísimo volumen de los migrantes peruanos en Arica, solo 892 niños de esa nacionalidad estudian en escuelas de la región, un tercio menos que los bolivianos (Seremi, 2015).

La contrapartida de estos procesos es la existencia en Tacna de un mercado de bienes y servicios, en ocasiones más barato, en otras sencillamente más conveniente, que los chilenos usan con mucha frecuencia (Ubilla, 2016). Las cifras sobre este tipo peculiar de intercambio son imprecisas, pero es usual encontrar cálculos que hablan de compras oscilantes entre 80 y 100 millones de dólares anuales, y de números de visitantes que van desde unos cuantos miles hasta cerca de 100 mil durante las fiestas patrias chilenas que los ariqueños prefieren festejar en los restaurantes y casinos de Tacna. Algunos de ellos pernoctan en la ciudad, ocupando los hoteles urbanos. Otros realizan compras en los supermercados antes de partir de regreso. En otras palabras, la economía local de Tacna funciona con una escala que contempla los cientos de miles de compradores chilenos, relativamente más solventes, que a los fines estadísticos figuran como turistas.

La manera como el ocio enlaza a ambas ciudades expresa una interesante contradicción. A primera vista, el auge comercial de Tacna opera en detrimento de las operaciones comerciales de Arica, pues la ciudad peruana se convierte en una playa de ocio y en una proveedora de servicios baratos que impiden su desarrollo en la contraparte chilena. Y es así hasta cierto punto, y ello parece constituir una regularidad en los complejos urbanos transfronterizos, en que la parte más pobre -por sus precios y eventualmente mayor permisividad- es un lugar de esparcimiento preferido. Pero al mismo tiempo, el auge lúdico de Tacna -y en general el atractivo turístico del sur peruano- ha provocado un incremento consistente de la actividad turística de Arica, a pesar de que la ciudad no ha logrado adaptarse a la flexibilidad de servicios que esta actividad requiere. ${ }^{14}$

14 Según datos del Sernatur, obtenidos en el marco de la Ley de Transparencia, entre 2008 (cuando Arica se estrenaba como región administrativa) y 2015 , se ha producido un incremento del $58 \%$ del número de hoteles registrados, un $18 \%$ del número de habitaciones y en un $26 \%$ el de camas. El número de restaurantes y ca-
Más allá del mundo formal, registrado o registrable, el tránsito masivo de personas en una frontera notablemente permisiva genera otros tipos de flujos económicos que tienen un impacto crucial en la economía de ambas ciudades, y en particular de Arica.

El primero de estos flujos grises es sin lugar a dudas el llamado comercio hormiga de mercancías adquiridas en Tacna. Aunque en este comercio se involucran tanto ciudadanos peruanos, como chilenos. Estos últimos se apoyan en que cada uno de ellos tiene derecho a introducir cantidades considerables de mercancías (hasta mil dólares en cada viaje) compradas en el extranjero sin impuestos aduaneros, o pagando tasas muy bajas. Aunque muchos chilenos realizan estas compras para consumo familiar aprovechando la variedad de ofertas y el diferencial de precios -el mercado de Tacna es abastecido por una zona franca-, otros usan la franquicia para fines mercantiles. Si tenemos en cuenta el volumen de cruces anuales, y que una misma persona puede realizarlo reiteradamente, entonces habría que presumir que el término comercio hormiga es un eufemismo que encubre un vasto contrabando que repercute inevitablemente en el consumo de los ariqueños y resulta en empleos redituables para cientos de personas.

La modalidad de comercio hormiga que más personas peruanas involucra es el comercio de ropa usada (denominada "ropa americana") que regularmente entra a Arica por el puerto aprovechando las franquicias de la Zofri de Iquique, y luego es redistribuida, sea en el propio mercado ariqueño o introducida subrepticiamente en Tacna. La razón de esto último es que -una situación de incertidumbre legal típica de una frontera- el comercio de ropa usada es legal en Tacna por disposición municipal, pero ilegal en Perú, por lo que su entrada al territorio de ese país se produce mediante diversas prácticas de evitación en los controles establecidos.

A estas relaciones dadas en el ámbito económico se suman otras de tipo familiar, amistosas, políticas o profesionales, y que han ido construyendo un for-

feterías se incrementó en un $131 \%$. Aunque se trata de la proliferación de pequeños hoteles -el promedio de habitaciones por establecimiento era de 18-, ello indica una dinámica económica sustancial a escala local e inseparable de la relación transfronteriza. 
mato de reconocimientos mutuos que no solo asumen una compartición de afectos básicos, sino también una percepción de complementación. ${ }^{15}$ Ello opera, por ejemplo, en los medios empresariales y funcionarios, y de hecho esta región transfronteriza está cruzada por numerosas redes de contactos sociales y públicos que se han ido anidando al calor de algunas organizaciones de la sociedad civil y del estatal Comité de Integración y Desarrollo Transfronterizo (CIDF).

Inobjetablemente aquí estamos en presencia de un complejo urbano transfronterizo (Dilla, 2015); probablemente uno de los más intensos que existen en América del Sur, solo comparable a conglomerados como la Triple Frontera formada por Ciudad del Este, Foz de Iguazú y Puerto Iguazú (Giménez y Montenegro, 2010; Bello, 2012) o entre San Cristóbal y Cúcuta, en Venezuela y Colombia respectivamente (Valero, 2002). Pero esta intimidad no debe obnubilar la esencia contradictoria de la relación. Uno de los aspectos más polémicos de los estudios fronterizos ha consistido precisamente en la prevalencia de una concepción funcionalista que hace del equilibrio la razón de existencia del sistema. De hecho, las primeras aproximaciones teóricas a las regiones transfronterizas -dadas en una Europa en proceso de integración o de una Norteamérica que aún cifraba esperanzas fusionistas en el TLCinsistieron en un contrapunteo entre elementos de fricción y elementos de fusión, en el seno de dominios funcionales marcados por las dinámicas del mercado y de las políticas integracionistas (Herzog, 1990). Como si se tratara de tendencias excluyentes y diferentes, y de esta manera la transfrontericidad el ambiente fronterizo de Martínez (1994) - aparecía como un itinerario ciertamente accidentado, pero conducente a un equilibrio estable entre las partes.

15 El tema de las representaciones mutuas, por su delicadeza metodológica, requiere investigaciones más sostenidas. Hipotéticamente, a partir de las observaciones realizadas, pudiéramos adelantar que la percepción de lo peruano en Arica es fragmentada: una cosa es el peruano en Tacna y otra el migrante depauperado que se aglomera en torno al Terminal en pos de una oportunidad de vida. En cada caso, dada la intensidad de las relaciones, las percepciones están atenidas a las experiencias personales y/o sociales en estos intercambios.
No parece un tipo de enfoque sostenible. En la vida real, los sistemas, y entre ellos los sistemas transfronterizos presentes en las RTF, se organizan como escenarios jerárquicos y conflictivos. La mirada positivista que contabiliza los espacios de fusión y fricción -regresando al aparato conceptual de Herzog- es engañosa, pues en la vida real estos espacios se yuxtaponen, condicionando cada uno de los ámbitos y circuitos en que se expresa la relación contradictoria que anima la llamada transfrontericidad. Para decirlo en términos foucaultianos, la separación y el contacto se disciplinarizan en aras de la reproducción sistémica. Y es así, y es la segunda consideración, porque la relación fusión/fricción, no importa ahora como la consideremos, es fenoménica respecto a relaciones determinantes de poder, sea en los ámbitos de clase, de género, de etnia, etcétera.

La frontera que aquí analizamos no es una excepción. Aun cuando animada por vínculos cooperativos de funcionarios y activistas, por proyectos de una evidente vocación fusionista, por contactos cotidianos que no prescinden de la solidaridad, y por un discurso aperturista que en ocasiones troca los deseos por la realidad, esta frontera es fundamentalmente una relación asimétrica basada en la búsqueda de ganancias diferenciales que benefician a ambas partes, pero que -permítanme una propuesta hipotética- generan una transferencia neta de recursos hacia la parte chilena. Es Arica la que usa fuerza de trabajo devaluada en aquellos segmentos de mercados precarizados que -sea por razones de prestigio o de precios- los nativos no ocupan, y que permite a la ciudad beneficiarse de los salarios mayores que sus emigrantes reciben en las zonas mineras del Norte Grande. Y son los ariqueños quienes realizan buena parte de sus consumos en Tacna, una ciudad de precios tan bajos como sus ingresos per cápita, todos sustancialmente más bajos que los que promedia la ciudad chilena.

Reconozcamos que es un tema complejo que requiere análisis más sostenidos, pero es indudable que aquí estamos en presencia de lo que Sohn (2014) caracterizó como un modelo de relaciones transfronterizas cuyo principal propósito es la captura de valores mediante la explotación del diferencial de precios y de las ganancias transaccionales. 


\section{La tercera frontera}

La relación con Tacna tiene otra ventaja: refuerza la identidad local de Arica. Y lo hace frente a la que muchos actores de la ciudad más norteña de Chile han percibido como su némesis: Iquique, una dinámica ciudad costera situada a unos $300 \mathrm{~km}$ más al sur.

La relación entre Arica e Iquique ha estado marcada por una rivalidad que se manifiesta simbólicamente mediante un puesto de control cuasifronterizo ubicado en el pequeño poblado de Cuya, en la frontera entre las regiones de Arica y Parinacota, y Tarapacá, y que sugiere que el verdadero Chile comienza en ese punto hacia el sur. Es difícil sostener una conversación con algún ariqueño sobre la región que de alguna manera no culpe a Iquique de su mala suerte.

De cierto, entre Arica e Iquique se han producido varias inversiones de la fortuna a lo largo del tiempo, que han favorecido indistintamente a una en detrimento de la otra, con la consiguiente sedimentación de resentimientos. En toda la primera mitad del siglo XX, Iquique superó a su vecina por dos razones. Una, que era la capital consolidada de la región de Tarapacá, a la que Arica se incorporó tras la anexión de 1929. Y como tal, esta última ciudad acaparó las inversiones públicas y los empleos estatales que constituyen siempre una fuente básica de sobrevivencia vecinal en las pequeñas ciudades. Luego, porque Iquique pudo captar parte de los excedentes de la explotación salitrera y vivir, por lo menos hasta los años veinte, de una prosperidad comercial que ha dejado su huella en el elegante Paseo Baquedano. Nada de lo cual fue conocido por Arica, que, al decir de un periódico local en 1931, "no tiene vida propia que vive casi enteramente del tránsito de mercaderías y pasajeros de Bolivia y en menor escala con las provincias del sur del Perú" (citado por Pizarro y Ríos, 2010, p. 80).

La oportunidad de Arica llegó de la mano del único gobernante genuinamente populista que ha pasado por el Palacio de La Moneda, el general Carlos Ibáñez del Campo, mediante sus proyectos de liberalización portuaria y posteriormente de industrialización sustitutiva de importaciones a cargo de la llamada Junta de Adelanto de Arica. El tema es suficientemente conocido como para detenerme en él.
Baste decir que entre 1953 y por dos décadas Arica no solo consolidó su rol tradicional como entrepôt regional con la proclamación del Puerto Libre, sino también como una plaza industrial típicamente desarrollista, que, de acuerdo con Camus y Rosenblit (2011) llegó a albergar 11 plantas de ensamblaje de automóviles, 12 de fabricación de piezas, 11 de artículos electrónicos, 9 manufactureras varias y un centenar de pequeños talleres. Solo en un caso -el procesamiento de pescado- se usaba materia prima local de manera significativa.

Era un proyecto atado a un acto de voluntarismo político. Como todo lo que se produjo bajo la égida de la industrialización sustitutiva de importaciones, solo era sostenible en un contexto de fuertes exportaciones primarias y de un mercado interno protegido. Y su radicación en Arica agregaba un insumo particular de irracionalidad al localizar la producción a miles de kilómetros de lo que hubiera sido su mercado natural: el conglomerado urbano central. Fue un proyecto desarrollista típico de las ansias de nacionalización de las fronteras en América Latina -ciertamente tardío- que prescindía de la principal cualidad de Arica, su condición fronteriza, y solo miraba a los bordes de manera indirecta. Era, por consiguiente, un proyecto no sostenible que no podía sobrevivir a los apuntalamientos políticos que lo crearon.

Pero los ariqueños no han podido olvidar que fue ese período cuando la ciudad creció a un ritmo impresionante, superando definitivamente a Iquique. Y fue dotada de una infraestructura básica que aún pervive en sus discretos edificios públicos. La población creció de forma exponencial. En 1952 la población de Arica ( 23 mil habitantes) era la mitad de la que mostraba Iquique, pero en 1970 casi se había cuadruplicado y llegaba a los 88 mil habitantes contra solo 65 mil en la capital regional. Según Galdámez (2010, p. 94) estas reformas, y en particular la imagen del Puerto Libre se instalaron en el imaginario popular como "hito significativo" del progreso "que permanece vivo en la conciencia de los más ancianos y que se ha transmitido a las generaciones actuales como símbolo de las reivindicaciones más sentidas y eficaces que aún en la actualidad encabezan las demandas al Estado nacional”. Fue el único momento en que su emblemático puerto ope- 
ró como el punto de partida de cadenas productivas mayores localizadas en su territorio. En consecuencia, también fue el momento en que Arica se sintió más apegada a un Estado nacional que usualmente había aparecido distante e indiferente. ${ }^{16}$

Cuando el modelo ISI entró en crisis y el ajuste neoliberal manu militari replanteó los términos de la organización económica y social del capitalismo chileno, Arica regresó a su antiguo rol de intermediación portuaria, mientras que Iquique se estrenó como un nodo de servicios comerciales especializados en torno a su zona franca. Al comenzar el siglo, Iquique, junto a su conurbación Alto Hospicio, superaba ampliamente la población de Arica.

Lo que había sido un ajuste sistémico a una economía local insostenible (no importa ahora la factura ideológica de ese ajuste) ha sido narrado como una suerte de conspiración castrense, en la que Arica quedó relegada a ser pontón defensivo frente a Perú. De manera que el quiebre de la prosperidad ha sido explicado -y eventualmente canonizado- como el resultado adverso de un régimen político impresentable. Como si, pensando en términos de Tilly, el ámbito de la coerción dictatorial hubiera terminado avasallando al ámbito de la acumulación local.

Los testimonios abundan. En una encuesta aplicada a medio centenar de líderes locales, un grupo de investigadores de la Universidad de Tarapacá (2008, p. 21) confiesa la asiduidad de opiniones como ésta: "A mediados de los setenta el presidente (y general de Ejército) Augusto Pinochet, frente a un escenario de conflicto potencial con Perú, decide potenciar Iquique como zona de defensa y 'sacrifica a Arica' por su fragilidad geo-política”. Algunos años más tarde, un informe de una coalición de ONG dirigida a la Intendencia para la localización de inversiones era muy claro:

A fines de 1973, bajo el régimen de dictadura, el Estado central revierte en la región,

16 "Desde la perspectiva de los pueblos del interior de la provincia -anotan Galdámez y Ruz (2010, p. 259)- la existencia de la Junta de Adelanto de Arica supuso de un modo u otro recuperar vínculos de participación y de interacción con el Estado que habían estado adormecidos durante décadas anteriores". la descentralización por el centralismo, la integración regional por la lógica de enclave y posicionamiento militar, y el desarrollo industrial por la desindustrialización acelerada. La carencia de democracia hará que la región navegue sin rumbo de prosperidad por 17 ańos" (Consejo de la Ciudadanía, 2014, p. 3).

En 2016, en uno de los últimos actos de su mandato, el alcalde de la ciudad de Arica convocó a una coalición de actores políticos y económicos con el objetivo de conseguir una mayor autonomía que permitiera a la ciudad enfrentar la competencia desleal de Iquique. La prensa (Carrasco, 2016) lo citaba reclamando una zona franca comercial propia, similar a la Zofri de Iquique, que la mitología local percibe como la causa de la inequidad regional. El pasado retornó en el discurso de un diputado: "A pesar de las diferencias, lo importante es ponernos de acuerdo en esto. El mismo espíritu de comunidad como el que tuvo la Junta de Adelanto tenemos que retornar" [sic].

\section{A modo de conclusiones: las previsiones del futuro}

Una conclusión evidente de todo lo discutido hasta aquí es que la región transfronteriza que se articula en torno al eje urbano Arica-Tacna está constituida por el engarzamiento de numerosos ámbitos y circuitos de relacionamientos refractados por la escala local. Obviamente, no quiero decir que se trate de una situación parroquial. El sistema regional posee suficientes conexiones con el entorno global como para suponer que aquí presenciamos el funcionamiento de "estructuras jerárquicas de organización que pueden enlazar el trabajo local y particular con el logro del trabajo abstracto en el escenario mundial" (Harvey, 1990, p. 425), todo lo cual, por su importancia, merece un tratamiento específico.

Pero es indudable que la región mantiene un sello local considerable, que de alguna manera fija sus características espaciales y temporales. Por ejemplo, no hay presencia directa de grandes compañías transnacionales, los vínculos trasfronterizos aún están coaccionados por la geopolítica (el caso de la relación 
con Bolivia) y la inmensa movilidad humana sigue teniendo un fuerte sello vecinal. Y por ello, la región aún conserva ese estilo de feria vernácula que ya se ha perdido en otras localidades de los dos países involucrados.

Es una situación que pudiera cambiar a la luz de los procesos de rearticulación territorial supranacional que ocurren en América del Sur y del desplazamiento de los núcleos más activos del capitalismo hacia el océano Pacífico. Y que pudiera tener efectos fundamentales sobre la región, al menos en tres sentidos que quiero presentar brevemente: la economía, la política y la identidad cultural.

La primera cuestión tiene que ver con la siempre deseada meta del desarrollo económico, es decir, cómo la región puede conseguir un proceso sustentable de crecimiento a partir de cadenas productivas y de servicios. Y desde ahí, generar procesos de inclusión social, de mejoramiento de las condiciones de vida de la población y de formación de capital humano de alta calidad, siempre en un marco de relación amistosa con el medio ambiente.

Ésta ha sido una preocupación recurrente tanto del Estado como de la sociedad civil y de los empresarios locales, y al efecto existen diversas propuestas que dan cuenta de necesidades específicas. Son usuales demandas como un puerto libre, una zona franca comercial, la construcción de obras viales y sociales, la irrigación de los valles de Lluta y Azapa, etcétera. Pero aun considerando que son todas acciones deseables, casi huelga recalcar que no implican per se ese desarrollo si ignoran la compleja realidad que afronta la región. Pues el futuro de Arica depende crecientemente de una dinámica que rebasa las fronteras nacionales y que solo podrá ser asumida desde políticas positivas que tiendan a fortalecer la competitividad de la región en un escenario transfronterizo más complejo y vasto que el que hoy enfrenta.

El Norte Grande chileno es parte de varias propuestas de reterritorialización en torno a los llamados corredores bioceánicos que se diseñan desde la Iniciativa para la Integración de la Infraestructura Regional Sudamericana (IIRSA). Estos corredores implican arreglos institucionales y normativos, infraestruc- tura, mayores niveles de conectividad, sistemas de transportes y relaciones comunitarias óptimas, pero no son meros módulos técnicos en formación, sino también, y sobre todo, redefiniciones drásticas de las escalas espaciales jerárquicas en función de centros económicos regionales y mundiales. Al decir de Schweitzer (2015, p. 76), buscan "adaptar los territorios a las exigencias del mercado mundial y de las grandes empresas, de conectar los grandes centros de producción y consumo mediante la diversificación de los medios y modos de transporte" y a partir de ahí "determinar nuevas situaciones de competitividad o inviabilidad" de regiones, circuitos productivos y sectores sociales.

Se trata de varios proyectos territoriales llamados a enlazar con la costa chilena a regiones de Paraguay, Bolivia (Santa Cruz y Cochabamba, Oruro, La Paz), el sur de Perú, las provincias argentinas de Salta y Jujuy, y los estados del Mato Grosso y el conglomerado económico de São Paulo y Puerto Suárez en Brasil (Inoztrosa y Bolívar, 2004). En referencia al llamado Zicosur -probablemente el proyecto más avanzado en esta dirección, que incluye los territorios de los corredores Central y de Capricornio-Colacrai (2016) - calculaba 40 millones de habitantes y 4,2 millones de $\mathrm{km}^{2}$ y destacaba que:

Entre sus funciones principales encontramos la de posibilitar la discusión y diseño de políticas desde la conjunción de lo público y privado, proyectar una oferta exportable común competitiva, basada en las ventajas que ofrece del lado chileno por la infraestructura portuaria existente para acceder a los mercados demandantes de la producción común, especialmente los del Asia Pacífico (p. 93).

Arica se ubica en este escenario como parte de un eje que se inicia en Antofagasta-Mejillones por el sur y llega hasta Ilo-Matarani por el norte, llamado a funcionar como una red de puertos pivotales de contactos con el Asia suroriental. Un eje portuario en el que se instalan con igual fuerza la competencia y la cooperación. Aun asumiendo que estos corredores solo puedan materializarse parcialmente, es indudable que todo ello significa para la región de Arica un reto desde más de un punto de vista. 
Obviamente, Arica pudiera colocarse en él simplemente como lo que hoy es: un puerto intermediario de la economía de economías regionales gravitantes. Pero si de lo que se trata es de dar un paso adelante, habría que analizar cómo convertir al puerto de Arica-siempre en el marco del eje antes mencionado- en un pivote de articulación de un clúster proveedor de bienes y servicios, capaz de organizar los flujos mercantiles a una escala regional, y agregador de valor. $Y$ hacerlo, implica pensar esta región desde una concepción de competitividad sistémica (Messner, 1996) a partir de la generación de políticas y consensos a diferentes niveles (macro, micro, meso y meta) y que, dada su condición fronteriza, involucra tanto a los agentes locales y nacionales como transfronterizos.

Esto último nos conduce directamente al segundo eje problemático, el campo propiamente político, concerniente a la institucionalidad, normatividad y prácticas en el ámbito público y en particular en el campo estatal.

Como Santis ha puntualizado -y es evidente en muchos pronunciamientos públicos y en la propia actividad académica-, el Estado chileno ha tendido a comportarse y percibirse -con un marcado sello ratzeliano- como "una entidad estrictamente geográfica o espacial". Al mismo tiempo, es posible advertir una evolución positiva en este sentido, tanto de las propias definiciones de propósitos como de prácticas que superan los enunciados programáticos.

Las Fuerzas Armadas, por ejemplo, que en 1994 todavía hablaban de las zonas extremas (Arica es una de ellas) como un asunto de "conquista y consolidación de las fronteras internas" (citado por Arce, 2012, p. 142) han avanzado considerablemente en sus percepciones sobre el tema y ahora argumentan positivamente sobre "los flujos transfronterizos". ${ }^{17} \mathrm{Y}$

17 El Ministerio de Defensa (2010, p. 58) ha definido su accionar como dirigido a "establecer canales que den vitalidad a las zonas fronterizas, facilitar el flujo transfronterizo de personas y bienes y potenciar una relación normal, activa y de impacto ciudadano. Los países pueden encontrar a través de ellos un medio efectivo para dinamizar el desarrollo de las comunidades nacionales situadas en estos espacios geográficos, de manera tal que los habitantes cuenten en lo cotidiano con nuevas si bien es cierto que en general persisten definiciones de los perfiles institucionales notablemente conservadoras y proteccionistas, como apuntaban Ovando y Álvarez (2011) en referencia a la crucial Dirección de Fronteras y Límites (Difrol) - "preservar y fortalecer la integridad territorial del país"- es también cierto que ello no solo se ubica por detrás de los tiempos, sino del propio trabajo práctico de la $\mathrm{Di}$ frol en la creación de espacios de interacción como el ya mencionado Comité de Integración y Desarrollo Fronterizo. Por todo ello, no es casual que el plan estratégico de desarrollo de la región de Arica y Parinacota inicie sus propuestas atando la meta de "una región socialmente madura" a la "complementariedad con los países vecinos" (Gobierno Regional de Arica y Parinacota, 2009, p. 48).

Pero es indudable que los avances experimentados son insuficientes para las necesidades de la región.

En un primer plano, si el Estado chileno pretende la formulación de "buenas políticas" en esta región -aquellas que potencian las oportunidades y minimizan los perjuicios-, debe reconocer la necesidad de regímenes fronterizos coherentes, estimulados por la desestatización (un mayor rol de la sociedad civil y las comunidades), la desnacionalización (un mayor espacio para concertaciones transfronterizas) y la descentralización (mayor autonomía local) de la gestión pública. Justo lo que Leresche y Sáez (2001), desde la perspectiva europea, denominaban la evolución desde una perspectiva topocrática a una adhocrática y sináptica. Y finalmente adoptar un modus operandi más flexible, adaptado a las contingencias cambiantes de una interacción tan compleja.

En segundo lugar, todo lo aquí discutido tiene como telón de fondo la existencia de controversias territoriales y posicionales con Bolivia y Perú, lo que en el primer caso ha llevado a la suspensión de las relaciones diplomáticas plenas. A pesar de estas disrupciones, las relaciones transfronterizas se han desarrollado con fluidez, como si los problemas de Lima, La Paz y Santiago no fueran los problemas que atañen a las comunidades limítrofes involucradas. No discuto aquí de qué lado se encuentran las razones

oportunidades de bienestar en zonas que tradicionalmente han sido menos favorecidas". 
legales o políticas de cada diferendo. Solo anoto que el aprovechamiento óptimo de las oportunidades de un escenario como el antes descripto ameritaría un paso adelante en más de un tema de controversia y el encuentro con soluciones más imaginativas. Probablemente como aquellas que desde el siglo pasado han estado sugiriendo acuerdos trinacionales, con cesiones de soberanía y comparticiones jurisdiccionales, en función de metas superiores. Fue, por ejemplo, lo que Anaya (1987) imaginó hace tres décadas como un "fruto espectacular... sin precedentes en la historia universal".

Finalmente, es posible que Arica logre una excelente posición en el entramado transnacional antes descripto, que se resuelvan los diferendos fronterizos y que el Estado se atenga a las nuevas exigencias de la gobernabilidad. Pero incluso así quedará un reto: el de la brumosa identidad transnacional. Aun en los términos contradictorios que antes discutía, Arica incuba una transfrontericidad muy intensa que contiene una incipiente perspectiva multicultural, y por ende, cosmopolita, que merece una mejor vida que su disolución en los rigores del mercado. Para muchos fines, la región constituye un paso adelante en algunos de los problemas que encara la sociedad chilena según se expone a ese orden transnacional que deviene componente ideológico vital del capitalismo contemporáneo.

Corresponde a los actores locales imaginar otra integración, por abajo, a diferencia de esa otra de grandes puertos e inmensos contenedores. Otra integración que dé cuenta creativamente de la interacción de las diferencias. Al final, no importa cuánto se abran los mercados o cuán ágil discurra la política, la realidad de esta región seguirá siendo como sugirió una funcionaria ariqueña durante una entrevista en que abogaba con vehemencia por una convivencia sin diferendos: “...no importa quién mande en cada lugar, todo lo que pasa en Arica tiene que ver con lo que pasa en Tacna, y así será siempre”.

\section{Agradecimientos}

Este artículo se inscribe en el proyecto CONICYT/ FONDECYT/Regular 1150812, "La regionalización transfronteriza en el norte de Chile”. El autor agradece su apoyo a la Vicerrectoría de Innovación, Investigación y Postgrado de la Universidad Arturo Prat. De igual manera reconoce el apoyo brindado por Felipe Valdebenito, Nicolás González y Damary Vilca, todos asistentes de la investigación, y por la coinvestigadora Camila Álvarez.

\section{Referencias citadas}

Aduanas de Chile ( (2017). Anuario estadístico. Santiago de Chile: Andros.

Albó , X. (2000). Aymaras entre Bolivia, Perú y Chile. Estudios Atacameños, 19, 43-73.

Anaya, R. (1987). Arica Trinacional. La Paz: Los amigos del Libro.

Aranda, G., Ovando, C. y Corder, A. (2010). Experiencias paradiplomáticas en la región de Tarapacá y sus proyecciones regionales. Estudios Internacionales, 165, 33-743.

Arce, M. (2012). El Rol de la Defensa en el Desarrollo de las Fronteras Interiores. ANEPE http://www.anepe. cl/2012/05/el-rol-de-la-defensa-en-el-desarrollo-de-lasfronteras-interiores/ recuperado el 9.02 .16

Bello, D. (2012). La triple frontera del Paraná. Santiago: RIL.

Benedetti, A. y Laguado I. (2013). El espacio fronterizo chileno-argentino. En Núñez, A. et al. Fronteras en movimiento e imaginarios geográficos (pp. 451-483). Santiago: RIL.

Brettell, C. y Hollifield, J. (2015). Migration Theory. New York: Routledge.

Brockman, R. (2014). Bolivia, Chile, Perú y el mar: entre la obsesión y la indiferencia. En Molina, S. (Ed.). Cuadrar el círculo: las propuestas de solución al conflicto entre Chile y Bolivia (pp. 79-94). Santiago de Chile: LOM.

Camus, P. y Rosenblit, J. (2011). Aislamiento de la frontera norte de Chile: ¿problema u oportunidad? En Arenas, F., Núñez, A. y Salazar, A. El aislamiento geográfico: ¿problema u oportunidad? (pp. 59-73). Santiago: PUCCH.

Carrasco E. (2016). "Con una sola voz se unen por la autonomía de Arica”. La Estrella de Arica, 13 de agosto. 
http://www.estrellaarica.cl/impresa/2016/08/13/full/ cuerpo-principal/3/

Colacrai, M. (2016). Cuando la frontera dialoga: Singularidades de la relación argentino-chilena en las últimas décadas. Estudios Fronterizos, nueva época, 17(34), 85-99, julio-diciembre de 2016.

Consejo de la Ciudadanía (2014). Tenemos fe en Arica: Plan Arica Parinacota 2030, Arica.

Dilla, H. (2015). Los complejos urbanos transfronterizos en América Latina. Revista de Estudios Fronterizos, Nueva Época, 16(31), 15-38.

Dilla, H. (2016). Chile y sus fronteras: notas para una agenda de investigación. Polis, 44, Agosto.

Félix, G. et al. (1997). Desarrollo regional y servicios al productor en los corredores fronterizos del norte de México. En García de León, M. y Mungaray, I. (Eds.). Desarrollo fronterizo y globalización. México: ANUEIS.

Foucault, M. (2008). Topologías. Fractal, XIII(48), 39-62.

Galdámez, L. (2010). El discurso del Estado a través de la creación del Puerto Libre de Arica. En Díaz, A. y Pizarro, E. (Comps.). Arica Siglo XX (pp. 93-100). Santiago de Chile: Universidad de Tarapacá.

Galdámez, L. y Ruz, R. (2010). La Junta de Adelanto de Arica y John V. Murra. Dos lecturas sobre el desarrollo andino en el norte de Chile. Chungara. Revista de Antropología Chilena, 42(1), 257-270.

García, V. (2015). La centralidad de la periferia: la frontera norte de Chile en el contexto transfronterizo e internacional. En Correa, L. y Salas, A. (Eds.). Gobernabilidad, desarrollo y seguridad en las zonas extremas de Chile (pp. 2019-239). Santiago: ANEPE.

Giménez, V. y Montenegro, S. (2010). La triple frontera: dinámicas culturales y procesos transnacionales. Buenos $\mathrm{Ai}-$ res: Espacio.

Gobierno Regional de Arica y Parinacota (2009). Estrategia Regional de Desarrollo, Arica.

González, S. (2006). Densidad, integración y conflicto en la triple frontera. En La integración y el desarrollo social fronterizo (pp. 25-42). Bogotá: Convenio Andrés Bello.
González, S. (2009). El Norte Grande de Chile: la definición histórica de sus límites, zonas y líneas de fronteras, y la importancia de las ciudades como geosímbolos fronterizos. Revista historia social y de las mentalidades, 13(2), 12-37.

González, S. (2013). Heterotopía y utopía en la pampa salitrera. En González, S. (Ed.). La Sociedad del Salitre (pp. 215-238). Santiago de Chile: Universidad Arturo Prat/ RIL Editores.

González, S. y Ovando, C. (2016). "Emotivistas" bolivianos en la relación diplomática entre Bolivia y Chile en torno a la mediterraneidad. Estudios Internacionales, 183, 39-65.

Harvey, D (1990). Los límites del capitalismo y la teoría marxista. México: Fondo de Cultura Económica.

Harvey, D. (2003). El nuevo imperialismo. Madrid: AKAL.

Hein, C. (2011). Port cityscapes: a networked analysis of the built environment. In Hein, C. (Ed.). Port Cities: Dynamic Landscapes and Global Networks (pp. 1-25). London: Routledge.

Herzog, L. (1990). Where North Meets South. Austin, TX: University of Texas Press.

Inostroza, L. y Bolívar, A. (2004). Corredores bioceánicos: territorios políticos y estrategias de integración subregional. Análisis Económico, XIX(41), 153-174.

Jessop, B. (2001). The Political Economy of Scale. In Perkman, M. y Ling Sum, N. (Eds.). Globalization, Regionalization and Cross Border Regions (pp. 25-49). London: Palgrave.

Kearny, M. (2003). Fronteras y límites del Estado y el Yo al final del Imperio. Alteridades, 13(25), 47-62, enerojunio.

Leimgruber, W. (2005). Boundaries and Transborder Relations, or the Hole in the Prison Wall. GeoJournal 64(3), 239-248. DOI 10.1007/s10708-006-7185

Leresche, J. P. y Sáez, G. (2001). Political Frontiers Regimes: Towards Cross-Border Governance? En Perkman, M. and Ling Sum, N. (Eds.). Globalization, Regionalization and Cross Border Regions (pp. 77-98). London: Palgrave. 
Luhmann, N. (1997). Sociedad y sistema: la ambición de la teoría. Barcelona: Paidós.

Maiz, C. (2007). La cordillera de los Andes: de muro a portal. Revista de Literaturas Modernas, 37, 113-156.

Martínez, O. (1994). Border People: Life and Society in the United States-Mexico Borderland. Tucson, AZ: The University of Arizona Press.

Messner, D. (1996). Latinoamérica hacia la economía mundial: condiciones para el desarrollo de la competitividad sistémica. Buenos Aires: FES.

Ministerio de Defensa (2010). Libro de la Defensa Nacional de Chile, I Parte, http://www.defensa.cl/media/2010_libro_de_la_defensa_1.pdf, recuperado el 20.04.16.

Morin, E. (2000). Sociología. Madrid: Tecnos.

Núńez, A. et al. (2013). Fronteras en movimiento e imaginarios geográficos. Santiago de Chile: RIL.

Ovando, C. y Álvarez, C. (2011). La dimensión fronteriza de la política exterior de Chile: inmovilidad y emergencia de nuevas dinámicas. Estudios Fronterizos, 12(24), 75-94, Julio-Diciembre.

Peña, C. (2009). Vida al limite en la frontera con Perú (tres partes), CIPER, http://ciperchile.cl/2009/08/27/vida-allimite-en-la-frontera-con-peru-i-el-incontenible-flujodel-contrabando-hormiga/, consultado el 8.04.2016.

Pizarro, E. y Ríos, W. (2010). Entre franquicias y beneficios: una apuesta del gobierno para el desarrollo regional de Arica. En Díaz, A. et al. (Eds.). Arica, Siglo XX, 79-97. Universidad de Tarapacá.

Santis, H. (1998). El pensamiento geográfico-político de Ratzel en la geopolítica chilena. Revista de Geografía Norte Grande, 25, 135-140.

Sassen, S. (2010). Territorio, autoridad y derechos. Madrid: Katz Editores.

Schweitzer, M. (2015). La IIRSA en la UNASUR: cambios y continuidades. En Furlong, A., Netzahualcoyotzi, R. y Sandoval, J. M. (Comps.). Integración en el continente americano (I), Puebla: Benemérita Universidad Autónoma de Puebla.
Seremi (2015). Informe alumnos extranjeros Región de Arica y Parinacota, Arica, Departamento de Planificación y Presupuesto, mayo.

Sohn, C. 2014. Modelling Cross-Border Integration: The Role of Borders as a Resource, Geopolitics, 19(3), 587608, DOI: 10.1080/14650045.2014.913029

Tapia, M. y Parella, S. (2015). Las regiones fronterizas para el estudio de la migración y la circulación. En Guizardi, M. (Ed.). Las fronteras del transnacionalismo, Santiago: UCN / Ocho Libros.

Tarrius, A. (2000). Leer, describir, interpretar las circulaciones migratorias. México: Colegio de Michoacán.

Tilly, C. (1990). Coerción, capital y los Estados europeos. Madrid: Alianza Universidad.

TPA (2017). Memoria anual, http://portal.tpa.cl/tpaweb/ wp-content/uploads/2018/03/MEMORIA-TPA_2017. pdf

Ubilla, M. (2016). "Tacna y sus precios le ganan la pulseada al comercio local”. En La Estrella de Arica, 6 de marzo.

Universidad de Tarapacá (2008). Representaciones del poder de las élites regionales. Subsecretaría de Desarrollo Regional y Administrativo, Santiago de Chile.

Valero, M. (2002). Las fronteras como espacios de integración. Caracas: Tropykos.

Vicuña, J. T. y Rojas, T. (2015). Migración en Arica y Parinacota. Santiago de Chile: Servicio Jesuita de Migrantes.

Wallerstein, I. (1999). El moderno sistema mundial. México: Siglo XXI. 